\title{
Laboreal
}

Volume $14 \mathrm{~N}^{\circ} 1$ | 2018

O regresso ao emprego após um acidente de trabalho

\section{Do modo de existência dos objetos técnicos:} introdução

Texto original: Simondon, G. (1969). Introduction. In G. Simondon. Du mode d'existence des objets techniques (pp. 9-16). Paris: Aubier.

El modo de existencia de los objetos técnicos: introducción

Du mode d'existence des objets techniques: introduction

On the mode of existence of technical objects: introduction

\section{Gilbert Simondon}

Tradutor. João Viana Jorge

\section{OpenEdition}

Journals

\section{Edição electrónica}

URL: http://journals.openedition.org/laboreal/546

DOI: $10.4000 /$ laboreal. 546

ISSN: 1646-5237

\section{Editora}

Universidade do Porto

\section{Refêrencia eletrónica}

Gilbert Simondon, « Do modo de existência dos objetos técnicos: introdução », Laboreal [Online] Volume $14 \mathrm{~N}^{0} 1$ | 2018, posto online no dia 01 julho 2018, consultado o 23 setembro 2020. URL http://journals.openedition.org/laboreal/546 ; DOI : https://doi.org/10.4000/laboreal.546

Este documento foi criado de forma automática no dia 23 setembro 2020.

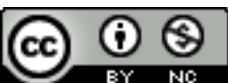

Laboreal está licenciado com uma Licença Creative Commons - Atribuição-NãoComercial 4.0 Internacional 


\section{Do modo de existência dos objetos técnicos: introdução}

Texto original: Simondon, G. (1969). Introduction. In G. Simondon. Du mode d'existence des objets techniques (pp. 9-16). Paris: Aubier.

El modo de existencia de los objetos técnicos: introducción

Du mode d'existence des objets techniques: introduction

On the mode of existence of technical objects: introduction

\section{Gilbert Simondon}

Tradução : João Viana Jorge

\section{REFERÊNCIA}

Texto original: Simondon, G. (1969). Introduction. In G. Simondon. Du mode d'existence des objets techniques (pp. 9-16). Paris: Aubier.

1 Este estudo é incentivado pela intenção de suscitar uma tomada de consciência do sentido dos objetos técnicos. A cultura constitui-se em sistema de defesa contra as técnicas; ora, essa defesa apresenta-se como defesa do homem supondo que os objetos técnicos não incluem a realidade humana. Quereríamos mostrar que a cultura ignora na realidade técnica uma realidade humana e que para desempenhar cabalmente o seu papel, a cultura deve incorporar os seres técnicos sob a forma de conhecimento e de sentido dos valores. A tomada de consciência dos modos de existência dos objetos técnicos deve ser alcançada pelo pensamento filosófico que se considera ter de cumprir nesse exercício um dever análogo ao que desempenhou na abolição da escravatura e na afirmação do valor da pessoa humana.

A oposição erigida entre a cultura e a técnica, entre o homem e a máquina, é falsa e sem fundamento; não encobre senão ignorância ou ressentimento. Mascara por detrás de um humanismo fácil uma realidade rica em esforços humanos e em forças materiais e que constitui o mundo dos objetos técnicos, mediadores entre a natureza e o homem. 
3 A cultura comporta-se perante o objeto técnico como o homem face ao estrangeiro quando se deixa arrastar pela xenofobia primitiva. 0 misoneísmo, orientado contra as máquinas, não é tanto o ódio pelo novo mas a recusa da realidade estrangeira. Ora este ser estranho é ainda humano e a cultura completa será a que permita descobrir o estrangeiro como humano. Identicamente a máquina é o estrangeiro; é o estrangeiro no qual está incluído o humano, mal conhecido, materializado, submisso, permanecendo todavia humano. A mais importante causa da alienação no mundo contemporâneo reside neste desconhecimento da máquina, que não é uma alienação causada pela máquina mas pelo não conhecimento da sua natureza e da sua essência, pela sua ausência do mundo dos significados e pela sua omissão na tabela de valores e de conceitos integrantes da cultura.

4 A cultura é desequilibrada porque reconhece determinados objetos como é o caso do objeto estético e lhes concede direitos de cidadania no mundo dos significados enquanto repele outros objetos, e em particular os técnicos, no mundo sem estrutura do que não possui significado mas apenas utilização, uma função útil. Perante esta recusa defensiva, proferida por uma cultura parcelar, os homens que conhecem os objetos técnicos e sentem o seu significado procuram justificar o seu julgamento concedendo ao objeto técnico o único estatuto atualmente valorizado para além do do objeto estético, o de objeto sagrado. Nasce então um tecnicismo destemperado que não é senão uma idolatria da máquina e, através dessa idolatria da máquina e através desta idolatria, por meio de uma identificação, uma aspiração tecnocrática ao poder incondicional. $\mathrm{O}$ desejo de poder consagra a máquina como meio de supremacia e faz dela o moderno filtro. $\mathrm{O}$ homem que quer dominar os seus semelhantes suscita a máquina androide. Abdica então perante ela e nela delega a sua humanidade. Procura construir a máquina de pensar sonhando poder construir a máquina do querer, a máquina do viver para poder postar-se detrás dela sem angústia, liberto de todos os perigos, isento de qualquer sentimento de fraqueza, triunfante, mediado pelo que inventou. Ora neste caso, a máquina tornada de acordo com a imaginação esse duplo do homem que é o robot, desprovido de interioridade, representa de modo bem evidente e inevitável um ser puramente mítico e imaginário.

Quereríamos mostrar precisamente que o robot não existe, que não é uma máquina, tanto quanto uma estátua não é um ser vivo, mas simplesmente um produto da imaginação e da fabricação fictícia, a arte da ilusão. Todavia a noção de máquina que existe na cultura atual incorpora em assaz larga medida esta representação mítica do robot. Um homem cultivado não se permitiria falar dos objetos ou das personagens pintadas numa tela como verdadeiras realidades dispondo de uma interioridade e de uma vontade boa ou maldosa. Esse mesmo homem fala todavia das máquinas que ameaçam o homem como se atribuísse a esses objetos uma alma e uma existência separada, autónoma que lhes conferisse o uso de sentimentos e de intenções dirigidas ao homem.

6 A cultura comporta assim duas atitudes contraditórias para com os objetos técnicos: por um lado trata-os como puras ensamblagens de matéria, desprovidas de verdadeiro significado e apresentando simplesmente uma dada utilidade. Por outro lado supõe que esses objetos são também robots e que estão animados com intenções hostis para com o homem ou representando para ele um permanente perigo de agressão, de insurreição. Considerando boa a conservação da primeira característica pretende impedir a 
manifestação da segunda e fala em colocar as máquinas ao serviço do homem, acreditando encontrar na redução à escravatura um meio de impedir qualquer rebelião.

7 De facto esta contradição inerente à cultura advém da ambiguidade das ideias relativas ao automatismo nas quais se esconde uma falha lógica. Os idólatras da máquina apresentam em geral o grau de perfeição de uma máquina como sendo proporcional ao grau de automatismo. Ultrapassando o que a experiência demonstra supõem que por um acréscimo e um aperfeiçoamento do automatismo chegar-se-á a reunir e interligar todas as máquinas entre si de modo a constituir uma máquina de todas as máquinas.

8 Ora, na realidade o automatismo é um assaz baixo grau de perfeição técnica. Para tornar automática uma máquina é preciso sacrificar muitas das possibilidades de funcionamento, muitas das possíveis utilizações. $O$ automatismo e a sua utilização sob a forma de organização industrial designado por automação, contém um significado mais económico ou social do que técnico. O verdadeiro aperfeiçoamento das máquinas, aquele do qual se pode dizer que eleva o grau de tecnicidade, corresponde não a um acréscimo de automatismo mas, pelo contrário, ao facto de que o funcionamento de uma máquina encerra uma certa margem de indeterminação. É essa margem que permite à máquina ser sensível a uma informação exterior. É devido a essa sensibilidade da máquina à informação que um equipamento técnico pode concretizarse, bem melhor do que por um aumento do automatismo. Uma máquina totalmente automática, completamente fechada sobre si própria num funcionamento prédeterminado não poderia fornecer senão resultados reduzidos. A máquina dotada de alta tecnicidade é uma máquina aberta e o conjunto das máquinas abertas pressupõe o homem como organizador permanente, como intérprete vivo de umas máquinas em relação às outras. Longe de ser o vigilante de uma tropa de escravos o homem é o organizador permanente de uma sociedade de objetos técnicos que têm necessidade dele como os músicos necessitam do maestro. Este não pode dirigir os músicos senão porque toca como eles, tão empenhadamente como eles, a peça executada; modera-os ou pressiona-os mas é também moderado e pressionado por eles; de facto, através dele o grupo de músicos modera e pressiona cada um deles, é para cada um deles a forma móvel e atual do grupo em vias de existir; é o intérprete recíproco de todos em relação a todos. Assim o homem tem por função ser o coordenador e o inventor permanente das máquinas à sua volta. Está entre as máquinas que operam com ele.

9 A presença do homem nas máquinas é uma invenção perpetuada. $O$ que reside nas máquinas é realidade humana, gesto humano fixado e cristalizado em estruturas que funcionam. Estas estruturas têm necessidade de serem mantidas no decurso do seu funcionamento e a maior perfeição coincide com a maior abertura, com a maior liberdade de funcionamento. As máquinas de calcular modernas não são puros autómatos; são entidades técnicas que para além dos seus automatismos de adição (ou de decisão por funcionamento de osciladores elementares) possuem muito vastas possibilidades de comutação dos circuitos que permitem codificar o funcionamento da máquina restringindo a sua margem de indeterminação. É graças a esta margem primitiva de indeterminação que a mesma máquina pode extrair raízes cúbicas ou traduzir um texto simples, composto com um pequeno número de palavras e de expressões, de uma língua para outra.

10 É ainda por intermédio desta margem de indeterminação e não pelos automatismos que as máquinas podem ser agrupadas em conjuntos coerentes, trocar informação umas com as outras por intermédio do coordenador que é o intérprete humano. Mesmo 
quando a troca de informação é direta entre duas máquinas (como entre um oscilador piloto e um outro sincronizado por impulso), o homem intervém como o ser que regula a margem de indeterminação a fim de que seja adaptada à melhor troca possível de informação.

Ora pode perguntar-se que homem pode realizar em si próprio a tomada de consciência da realidade técnica e introduzi-la na cultura. Essa tomada de consciência dificilmente pode ser levada a cabo por aquele que estiver ligado a uma única máquina pelo trabalho e a constância dos gestos quotidianos; a relação de uso não é favorável à tomada de consciência porque o recomeço habitual esbate-se no estereótipo dos gestos adaptados à consciência das estruturas e dos funcionamentos. $O$ facto de governar uma empresa utilizando máquinas, ou a relação de propriedade, não é mais útil do que o trabalho para essa tomada de consciência: cria pontos de vista abstratos sobre a máquina, avaliada pelo preço e resultados do funcionamento mais do que por si própria. 0 conhecimento científico que vê no objeto técnico a aplicação prática de uma lei teórica também não está ao nível do domínio técnico. Essa tomada de consciência pareceria ser preferencialmente o campo do engenheiro de organização que seria como que o sociólogo e o psicólogo das máquinas, vivendo no meio dessa sociedade de entidades técnicas das quais é a consciência responsável e inventiva.

Uma verdadeira tomada de consciência das realidades técnicas apreendidas na sua significação corresponde a uma pluralidade aberta de técnicas. Não pode aliás decorrer de outra maneira porque um conjunto técnico mesmo pouco extenso engloba máquinas cujos princípios de funcionamento relevam de domínios científicos muito diferentes. A especialização dita técnica corresponde mais do que frequentemente a preocupações exteriores aos objetos técnicos propriamente ditos (relações com o público, forma particular de comércio) e não a uma espécie de esquemas de funcionamento inerentes aos objetos técnicos; é a especialização segundo as diretivas exteriores aos técnicos que cria a estreiteza de vistas censurada aos técnicos pelo homem cultivado que considera que deles se distingue: trata-se mais de uma estreiteza de intenções, de finalidades, do que de uma estreiteza de informação ou de intuição das técnicas. Muito raras são, nos nossos dias, as máquinas que não sejam, ao mesmo tempo mecânicas, térmicas e elétricas.

Para reatribuir à cultura o carácter verdadeiramente geral que perdeu é preciso poder reintroduzir-lhe a consciência da natureza das máquinas, das suas mútuas relações e das suas relações com o homem e dos valores implicados nessas relações. Essa tomada de consciência requer a existência, ao lado do sociólogo e do psicólogo, do tecnólogo ou mecanólogo. Além disso os esquemas fundamentais de causalidade e de regulação que constituem uma axiomática da tecnologia devem ser ensinados universalmente como o são os fundamentos da cultura literária. A iniciação às técnicas deve ser colocada no mesmo plano que a educação científica; ela é tão desinteressada quanto a prática das artes e domina tanto as aplicações práticas quanto a física teórica; pode atingir o mesmo grau de abstração e de simbolização. Uma criança deveria saber o que é uma autorregulação ou uma reação positiva como sabe o que são teoremas matemáticos.

Esta reforma da cultura, procedendo por extensão e não por destruição, poderia reatribuir à cultura atual o real poder regulador que perdeu. Base de significados, de meios de expressão, de justificações e de formas, uma cultura estabelece entre os que a possuem uma comunicação regulatória; saindo da vida do grupo anima os gestos dos que asseguram as funções de comando fornecendo-lhes normas e esquemas. Ora antes 
do grande desenvolvimento das técnicas a cultura incorporava a título de esquemas, de símbolos, de qualidades, de analogias, os principais tipos de técnicas dando lugar a uma experiência vivida. Pelo contrário, a cultura atual é a cultura antiga incorporando como esquemas dinâmicos o estado das técnicas artesanais e agrícolas dos séculos passados. $\mathrm{E}$ são esses esquemas que servem de mediadores entre os grupos e os seus chefes impondo, devido à sua inadequação às técnicas, uma distorção fundamental. O poder torna-se literatura, arte da opinião, pleito de defesa das verosimilhanças, retórica. As funções diretivas são falsas porque não mais existe entre a realidade governada e os seres que governam um código adequado de relações: a realidade governada comporta homens e máquinas; o código não assenta senão na experiência do homem trabalhando com utensílios ele próprio enfraquecido e longínquo porque os que empregam esse código não acabam, como Cincinnatus, de abandonar os manípulos da charrua. 0 símbolo enfraquece tornando-se em simples jogo de palavras, o real está ausente. Uma relação reguladora de causalidade circular não pode estabelecer-se entre o conjunto da realidade governada e a função autoritária: a informação não mais chega porque o código se tornou inadequado ao tipo de informação que deveria transmitir. Uma informação que exprima a existência simultânea e correlativa dos homens e das máquinas deve comportar os esquemas de funcionamento das máquinas e os valores que implicam. É preciso que a cultura se retorne geral, quando na verdade se especializou e empobreceu. Esta extensão da cultura, suprimindo uma das principais fontes de alienação e restabelecendo a informação regulatória, possui um valor político e social: pode fornecer ao homem meios para pensar a sua existência e a sua situação em função da realidade que o envolve. Este trabalho de alargamento e de aprofundamento da cultura tem também um papel caracteristicamente filosófico a desempenhar porque conduz à crítica de um certo número de mitos e de estereótipos, como o do robot, ou dos autómatos perfeitos ao serviço de uma humanidade preguiçosa e plenamente satisfeita.

Para operacionalizar esta tomada de consciência é possível procurar definir o objeto técnico em si mesmo pelo processo de concretização e de sobredeterminação funcional que lhe dá consistência, no termo de uma evolução, provando que não poderia ser considerado um simples utensílio. As modalidades desta génese permitem apreender os três níveis do objeto técnico e a sua coordenação temporal não dialética: o elemento, o indivíduo, o conjunto.

Sendo o objeto técnico definido pela sua génese é possível estudar as relações entre ele e as outras realidades, em particular o homem no estado adulto e a criança.

Enfim, considerado como objeto de um julgamento de valores, o objeto técnico pode suscitar atitudes muito diferentes conforme é tomado ao nível do elemento, ao nível do indivíduo ou ao nível do conjunto. Ao nível do elemento o seu aperfeiçoamento não introduz qualquer perturbação que engendre angústia por conflito com os hábitos adquiridos: é o clima otimista do século XVIII, introduzindo a ideia de um progresso contínuo e indefinido, comportando melhorias constantes no destino do homem. Pelo contrário, o indivíduo técnico torna-se durante uns tempos o adversário do homem, o seu concorrente, porque o homem centralizava em si a individualidade técnica do tempo em que só existiam ferramentas; a máquina toma o lugar do homem porque o homem desempenhava uma função de máquina, de portador de ferramentas. A esta fase corresponde uma noção dramática e apaixonada do progresso tornando-se violação da natureza, conquista do mundo, captação das energias. Esta vontade de 
poderio exprime-se através da desmesura tecnicista e tecnocrática da era da termodinâmica que provoca uma reviravolta ao mesmo tempo profética e cataclísmica. Enfim, ao nível dos conjuntos técnicos do século XX, o energetismo termodinâmico é substituído pela teoria da informação cujo conteúdo normativo é eminentemente regulador e estabilizador: o desenvolvimento das técnicas aparece como uma garantia de estabilidade. A máquina, como elemento do conjunto técnico torna-se no que aumenta a quantidade de informação, o que acrescenta a negentropia [1], o que se opõe à degradação da energia: a máquina, produto da organização, da informação, é, como a vida e com a vida, o que se opõe à desordem, ao nivelamento de todas as coisas tendentes a privar o universo dos poderes de mudança. A máquina é aquilo por que o homem se opõe à morte do universo; relenta, como a vida, a degradação da energia e torna-se estabilizadora do mundo.

Esta modificação do olhar filosófico sobre o objeto técnico anuncia a possibilidade de uma introdução da entidade técnica na cultura: essa integração, que não conseguiu efetuar-se nem ao nível dos elementos nem ao nível dos indivíduos de maneira definitiva poderá sê-lo com mais hipóteses de estabilidade ao nível dos conjuntos; a realidade técnica tornada regulatória poderá integrar-se na cultura, regulatória na sua essência. Esta interpretação não podia fazer-se senão por adição no tempo em que a tecnicidade residia nos elementos, por rutura e revolução no tempo em que a tecnicidade residia nos novos indivíduos técnicos; hoje a tecnicidade tende a residir nos conjuntos; pode então tornar-se um fundamento da cultura à qual trará um poder de unificação e de estabilidade, tornando-a adequada à realidade que exprime e regulamenta.

\section{NOTAS}

1. Nota do tradutor: Negentropia corresponde à capacidade de proporcionar integração e organização do sistema de informação. 